\title{
Three-dimensional analysis of cervical spine segmental motion in rotation
}

Xiong Zhao, Zi-xiang Wu, Bao-jun Han, Ya-bo Yan, Yang Zhang, Wei Lei

Department of Orthopaedics, Xijing Hospital, the Fourth Military Medical University, Xi'an, China

Submitted: 4 November 2011

Accepted: 18 March 2012

Arch Med Sci 2013; 9, 3: 515-520

DOI: 10.5114 /aoms.2013.35325

Copyright $\odot 2013$ Termedia \& Banach

\section{Abstract}

Introduction: The movements of the cervical spine during head rotation are too complicated to measure using conventional radiography or computed tomography (CT) techniques. In this study, we measure three-dimensional segmental motion of cervical spine rotation in vivo using a non-invasive measurement technique.

Material and methods: Sixteen healthy volunteers underwent three-dimensional $\mathrm{CT}$ of the cervical spine during head rotation. Occiput (Oc) - T1 reconstructions were created of volunteers in each of 3 positions: supine and maximum left and right rotations of the head with respect to the bosom. Segmental motions were calculated using Euler angles and volume merge methods in three major planes. Results: Mean maximum axial rotation of the cervical spine to one side was $1.6^{\circ}$ to $38.5^{\circ}$ at each level. Coupled lateral bending opposite to lateral bending was observed in the upper cervical levels, while in the subaxial cervical levels, it was observed in the same direction as axial rotation. Coupled extension was observed in the cervical levels of C5-T1, while coupled flexion was observed in the cervical levels of Oc-C5.

Conclusions: The three-dimensional cervical segmental motions in rotation were accurately measured with the non-invasive measure. These findings will be helpful as the basis for understanding cervical spine movement in rotation and abnormal conditions. The presented data also provide baseline segmental motions for the design of prostheses for the cervical spine.

Key words: cervical spine, segmental motion, coupled motion, rotation, in vivo.

\section{Introduction}

One of the fundamental functions of the cervical spine is to assist and control motion of the head and neck. When the kinematics of the neck is disrupted, the abnormal motion may contribute to clinical symptoms. Many investigators have provided data in support of the hypothesis that abnormalities in intervertebral motion provide important diagnostic information in the evaluation of patients reporting neck or related complaints [16]. Although disorders of the cervical spine can affect motion in many different geometric planes, abnormalities in sagittal plane motion have been the focus of most research. Flexion-extension radiographs are commonly used in clinical practice to help identify abnormalities in motion within patients with suspected cervical spine disorders [7]. There has been some controversy as to whether excessive motion on flexion-extension radiographs is associated with low neck pain or degenerative disc disease

\author{
Corresponding author: \\ Wei Lei \\ Department of Orthopaedics \\ Xijing Hospital \\ the Fourth Military \\ Medical University \\ No. 17 Changlexi Road \\ Xi'an Shaanxi Province \\ PR China, 710032 \\ Phone: +862984772132 \\ Fax: +862984772132 \\ E-mail: wlspine@163.com.cn
}


$[6,7]$. Spinal instability, and axial rotational instability in particular, has been implicated in the pathogenesis of chronic low neck pain.

Axial rotation of the cervical spine is complicated by accompanying concomitant motions in lateral bending, flexion-extension, and translations, as so-called coupled motion [8]. The use of radiographs has been shown to be limited by poor accuracy and impracticality of measuring out-ofplane rotations $[9,10]$. In addition, the range of motion measured in many radiographic studies is affected by the variability in voluntary efforts that the subject applies at the time of examination and also can be limited because of pain. Other twodimensional methods for measuring axial rotation, as opposed to flexion-extension, have involved magnetic resonance imaging (MRI) scanning of subjects in various rotated positions $[11,12]$. While these studies were non-invasive and controlled for voluntary motions, they could only determine changes in vertebral motion around one axis. It has been suggested that coupled motions could play an important role in determining spinal instability [13]. In this study, we measured the three-dimensional segmental motion of the cervical spine during rotation in vivo using a non-invasive measurement technique. These findings will be helpful as the basis for understanding cervical spine movement in rotation and abnormal conditions. The presented data also provide baseline segmental motions for the design of prostheses for the cervical spine.

\section{Material and methods}

\section{Acquisition of 3D CT}

Sixteen healthy, asymptomatic volunteers participated in the current study (mean age: $26.5 \pm 3.4$ years (mean \pm SD); 8 males and 8 females). Each subject signed an approved informed consent form. Computed tomography (CT) was used to calculate three-dimensional motion of the cervical vertebral bodies for this study. Subjects were placed supine on the CT table and asked to rotate their heads from neutral to maximum rotation while 3D images were obtained. Subjects always rotated their head on a plane perpendicular to the CT table by keeping both of their eyes on the positioning beam of the CT machine throughout head rotation, and their shoulders were fixed to the table with the band. If the extreme rotations were severely uncomfortable for the subjects, a lower value for full rotation would be used and recorded for subsequent analysis.

\section{Processing of 3D CT image}

The 1.0-mm-thick axial slices from the CT scanner were imported into a three-dimensional reconstruction software package (Mimics, Materialise
Inc., Ann Arbor, MI), where a threshold level to define the cortical shell was selected. Each vertebral body was segmented based on the threshold level. These reconstructions were then imported into the software package ProEngineer 2000i (Parametric Technology Corp., Needham, MA) where a three-dimensional solid model was created and the principal moment, principal axes and centroid of each vertebra were calculated. Using the theory of rigid body mechanics, the principal axes at the centroid of a solid body were rotated with that body so that the amount of rotation was determined. The inertial property values were then input into a custom program (Matlab, MathWorks Inc., Novi, $\mathrm{MI})$ that used Euler angles to determine initial rotations and translations about the centroid between two vertebral bodies based on methods described by Panjabi et al. and other authors [14]. A volume merge method was created with custom software program in Microsoft Visual C++. NET 2003 with Microsoft Foundation Class programming environment (Microsoft Corp., Redmond, WA) and was further used to refine the above-mentioned Eigen vector method [15]. In the volume merge method, a vertebral body in the neutral position (the moving vertebra) was virtually rotated and translated toward the same body in a rotated position (the stationary target).

\section{Coordinate system}

Three major axes of rotation were examined (flexion-extension, lateral bending, and axial rotation) for each vertebral body. An order of axial/flexion-extension/lateral bending rotation was used in this study for determining the Euler angles $[16,17]$. Positive values indicated left axial rotation, left lateral bending, and flexion. In addition, translations of the centroid from neutral position to rotated positions were calculated in the three major planes (frontal, x; sagittal, y; and axial, z). Positive values for translations were left, posterior, and superior motions (Figures 1 and 2).

\section{Evaluation of accuracy}

Mean absolute rotational error was $0.01^{\circ}$ for flexion-extension, $0.01^{\circ}$ for lateral bending, and $0.005^{\circ}$ for axial rotation. Mean absolute translational error was $0.02 \mathrm{~mm}$ for superoinferior translation, $0.01 \mathrm{~mm}$ for anteroposterior translation, and $0.02 \mathrm{~mm}$ for lateral translation.

\section{Motion analysis}

Segmental rotations and translations were calculated as the motion from supine to either left or right rotations. Analysis for rotations and translations was performed using a one-way analysis of variance with Fisher's post hoc test to determine 

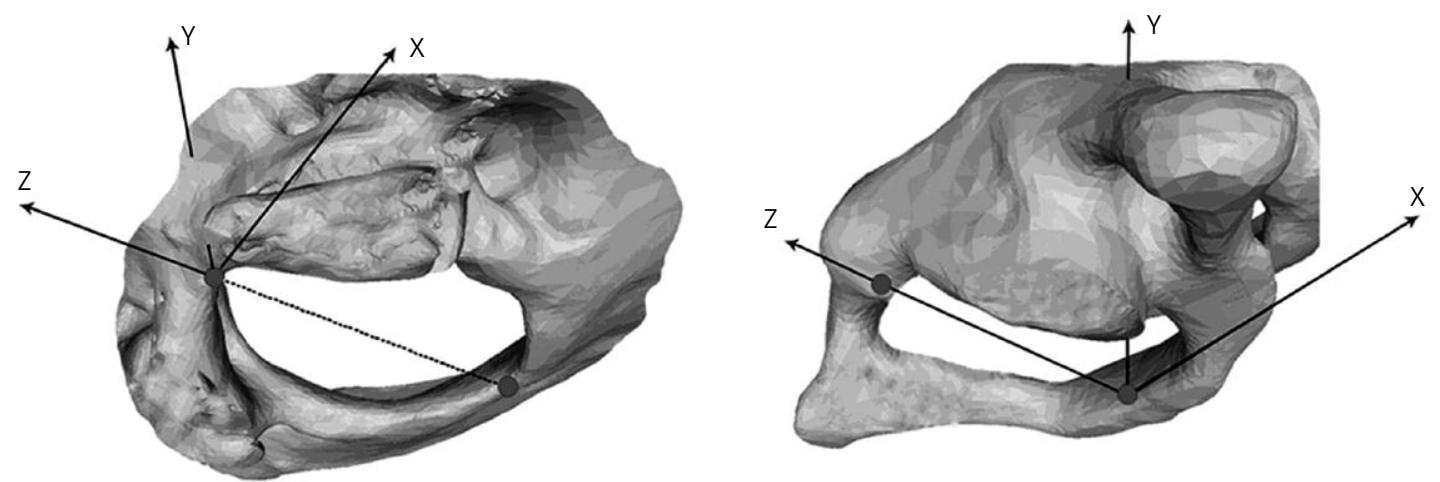

Figure 1. Anatomical orthogonal coordinate system for Oc and C1

differences based on spinal level and direction of motion. The significance level was set to $p<0.05$ for all analyses.

\section{Results}

Mean ( \pm SD) angle of axial rotation of the head (Oc-T1) from neutral to maximum was $65.3^{\circ} \pm 5.2^{\circ}$. Coupled lateral bending in the same direction as axial rotation was $15.1^{\circ} \pm 3.6^{\circ}$ and coupled flexion was $16.7^{\circ} \pm 3.9^{\circ}$. Means and standard deviations for ranges of intervertebral motions to one side are displayed in Figures 3 and 4.

\section{Axial rotation}

Mean maximum axial rotation at each level of the axial cervical spine to one side was $2.4^{\circ} \pm 1.8^{\circ}$ at $\mathrm{Oc}-\mathrm{C} 1,38.5^{\circ} \pm 4.7^{\circ}$ at $\mathrm{C} 1-\mathrm{C} 2,3.1^{\circ} \pm 1.1^{\circ}$ at $\mathrm{C} 2-\mathrm{C} 3$, $4.0^{\circ} \pm 1.6^{\circ}$ at $\mathrm{C} 3-\mathrm{C} 4,5.3^{\circ} \pm 1.5^{\circ}$ at $\mathrm{C} 4-\mathrm{C} 5,4.6^{\circ} \pm 1.8^{\circ}$ at $\mathrm{C} 5-\mathrm{C} 6,2.3^{\circ} \pm 1.3^{\circ}$ at $\mathrm{C} 6-\mathrm{C} 7$, and $1.6^{\circ} \pm 0.9^{\circ}$ at $\mathrm{C} 7-$ T1. Maximum axial rotation was thus greater in $\mathrm{C} 3-$ C4, C4-C5 and C5-C6 than in other levels.

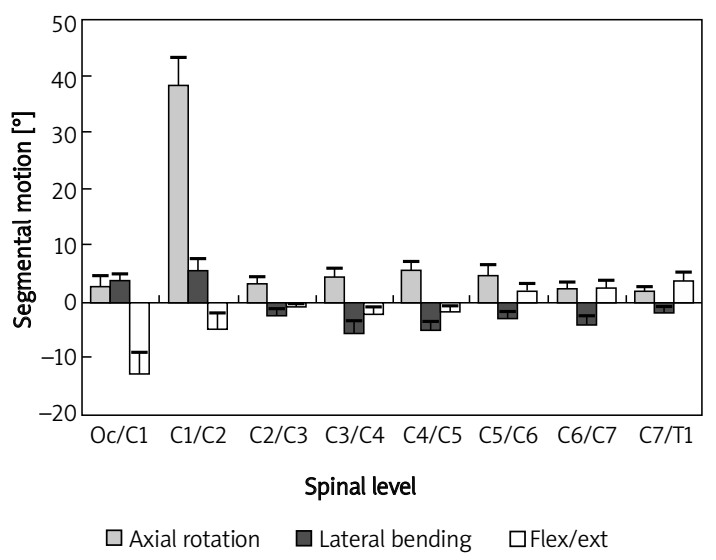

Figure 3. Segmental spine rotation for 16 asymptomatic subjects. Coupled lateral bending (LB) (+) represents the opposite direction of axial rotation (AR); coupled flexion-extension (F-E) $(+)$ represents flexion

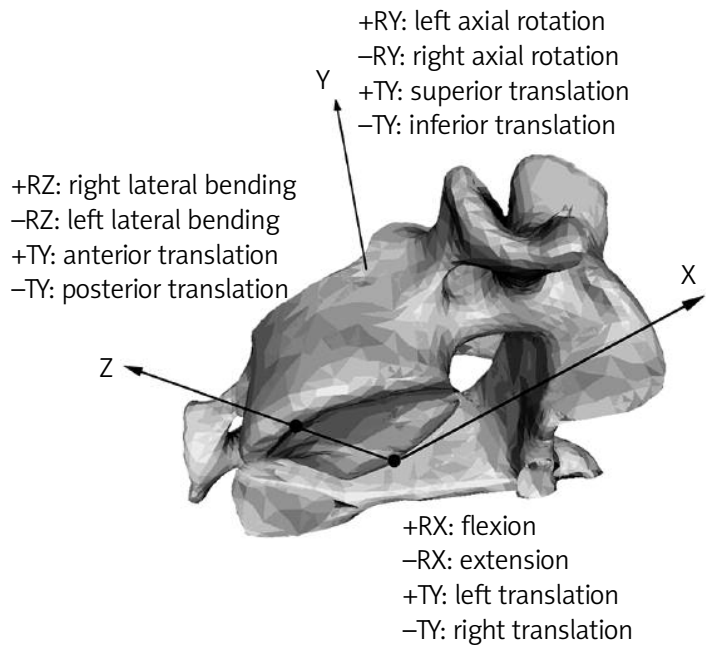

Figure 2. Anatomical orthogonal coordinate system for lower cervical spine

\section{Coupled lateral bending}

Coupled lateral bending with axial rotation was observed in the same direction as axial rotation at

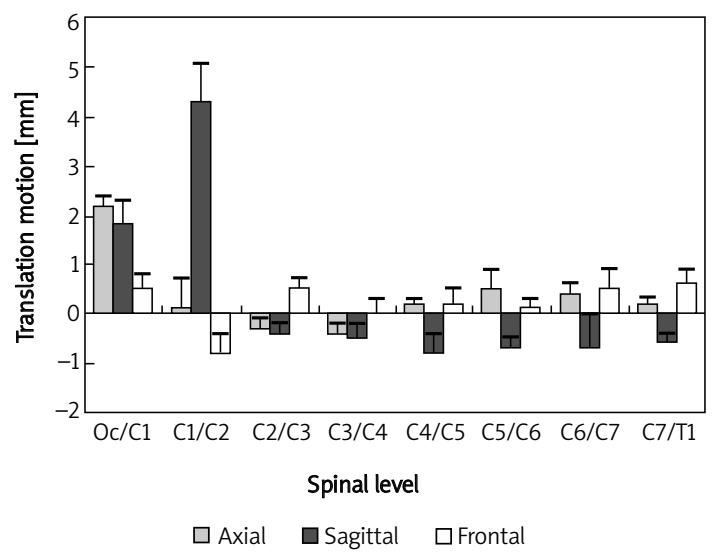

Figure 4. Segmental spine rotation for 16 asymptomatic subjects. Coupled translation (+) represents superior for superoinferior translation (SI-T), the same direction in the axial rotation for lateral translation (LT), and anterior for anteroposterior translation (AP-T) 
all levels except for $\mathrm{Oc}-\mathrm{C} 1$ and $\mathrm{C} 1-\mathrm{C} 2$. The means of lateral bending during maximum head rotation were $3.6^{\circ} \pm 1.3^{\circ}$ at $\mathrm{Oc}-\mathrm{C} 1,5.4^{\circ} \pm 2.0^{\circ}$ at $\mathrm{C} 1-\mathrm{C} 2,2.7^{\circ}$ $\pm 1.3^{\circ}$ at $\mathrm{C} 2-\mathrm{C} 3,5.9^{\circ} \pm 2.2^{\circ}$ at $\mathrm{C} 3-\mathrm{C} 4,5.4^{\circ} \pm 1.8^{\circ}$ at $\mathrm{C} 4$ $\mathrm{C} 5,3.1^{\circ} \pm 1.1^{\circ}$ at $\mathrm{C} 5-\mathrm{C} 6,4.2^{\circ} \pm 1.6^{\circ}$ at $\mathrm{C} 6-\mathrm{C} 7$, and $2.2^{\circ}$ $\pm 1.4^{\circ}$ at $\mathrm{C} 7-\mathrm{T} 1$. Similar to axial rotation, all participants displayed a greater degree of coupled lateral bending at $\mathrm{C} 3-\mathrm{C} 4, \mathrm{C} 4-\mathrm{C} 5, \mathrm{C} 5-\mathrm{C} 6$, and $\mathrm{C} 6-\mathrm{C} 7$ than in the other levels.

\section{Coupled flexion-extension}

Extension coupled with axial rotation occurred in the upper and middle cervical region (Oc-C1 $12.9^{\circ}$ $\pm 3.8^{\circ}, \mathrm{C} 1-\mathrm{C} 24.9^{\circ} \pm 2.6^{\circ}, \mathrm{C} 2-\mathrm{C} 31.1^{\circ} \pm 1.0^{\circ}, \mathrm{C} 3-\mathrm{C} 42.4^{\circ}$ $\pm 1.3^{\circ}, \mathrm{C} 4-\mathrm{C} 52.0^{\circ} \pm 1.2^{\circ}$ ), while in the lower cervical region, flexion was coupled with axial rotation ( $\mathrm{C} 5-$ C6 $\left.1.6^{\circ} \pm 1.4^{\circ}, \mathrm{C} 6-\mathrm{C} 72.2^{\circ} \pm 1.2^{\circ}, \mathrm{C} 7-\mathrm{T} 13.5^{\circ} \pm 1.5^{\circ}\right)$.

\section{Coupled translations}

Lateral translation coupled with axial rotation at the origin of coordinates was observed in the direction opposing axial rotation at all levels except for Co-C1, C1-C2 (Oc-C1 $1.8 \pm 0.5 \mathrm{~mm}, \mathrm{C} 1-\mathrm{C} 24.3$ $\pm 0.8 \mathrm{~mm}, \mathrm{C} 2-\mathrm{C} 30.4 \pm 0.2 \mathrm{~mm}, \mathrm{C} 3-\mathrm{C} 40.5 \pm 0.3 \mathrm{~mm}$, C4-C5 $0.8 \pm 0.4 \mathrm{~mm}, \mathrm{C} 5-\mathrm{C} 60.7 \pm 0.2 \mathrm{~mm}, \mathrm{C} 6-\mathrm{C} 70.7$ $\pm 0.3 \mathrm{~mm}, \mathrm{C} 7-\mathrm{T} 10.6 \pm 0.2 \mathrm{~mm})$. Coupled superoinferior translation of Oc relative to $\mathrm{C} 1$ with axial rotation was observed in superior (mean $2.2 \pm 0.2 \mathrm{~mm}$ ) directions. Other coupled anteroposterior and superoinferior translation with axial rotation was hardly seen.

\section{Discussion}

To measure these coupled motions, several studies have attempted to delineate coupling motion patterns of the cervical spine during rotation. More invasive techniques involve inserting wires into the spinous process of subjects to determine threedimensional motion [18]. While this method has proven more accurate than radiographs, its invasive nature limits its widespread clinical use. Other researchers have used biplanar radiography, where subjects are filmed from two directions simultaneously and three-dimensional motions are determined from anatomic landmarks in corresponding images $[19,20]$. There has been some concern with the accuracy of determining anatomic landmarks for biplanar radiography, as well as a lack of equipment for this method in typical clinical settings. Panjabi et al. [21], and Moroney et al. [22] observed in cadaver studies that axial rotation of the cervical spine accompanies lateral bending in the same direction as axial rotation, but no detailed descriptions of coupled flexion-extension were reported. In these in vitro studies, however, the cervical spines without the muscles might not accurately reflect physiological cervical motion. Mimura et al. attempted to document in vivo coupled motion with axial rotation using biplanar radiography but failed to accurately demonstrate complex coupled motion, as their methods depended greatly on subjective assessments by the examiner in tracking bony landmarks on plain radiographs [23]. To combat some of these limitations to threedimensional motion measurement, Lim et al. developed a three-dimensional imaging technique using parallel computed tomography (CT) scans to determine rotations and translations in individual cadaveric cervical vertebrae [9]. The authors illustrated that accurate measurements $\left(1 \mathrm{~mm}\right.$ and $\left.1^{\circ}\right)$ can be made using $\mathrm{CT}$ in vitro.

In our study, a non-invasive method was introduced to measure the in vivo cervical segmental rotation and translation with high accuracy. It has overcome several limitations of previous in vitro methods, such as the necessity to disrupt soft tissues for implantation of markers or rods, and a lack of physical muscular force [8]. The method used in the current study was a combination of the Eigen vector method and the volume merging method. The Eigen vector method was used in a previous study for measurement of orientation of a threedimensional computer cervical vertebral model created by cadaveric cervical vertebrae [9]. The accuracy of this method was expected to be $1^{\circ}$ under in vitro conditions, which was large in comparison to the expected cervical segmental motions in vivo.

Table I. Comparison of mean range (SD) of axial rotation on one side $\left(^{\circ}\right)$

\begin{tabular}{|lccccccccc|}
\hline & & OC-C1 & C1-C2 & C2-C3 & C3-C4 & C4-C5 & C5-C6 & C6-C7 & C7-T1 \\
\hline In vitro & & & & & & & & & \\
\hline W\&P (1978) & Cadaver & 0 & 47 & 9 & 11 & 12 & 10 & 9 & 8 \\
\hline Panjabi et al. [26] & Cadaver & 0 & 38.9 & 1.6 & 2.6 & 3.4 & 2.6 & 1.5 & - \\
\hline In vivo & & & & & & & & & \\
\hline Dvorak et al. [14] & CT & 4 & 41.5 & $3(2.5)$ & $6.5(2.3)$ & $6.7(2.3)$ & $7.0(2.4)$ & $5.4(2.3)$ & $2.2(2.1)$ \\
\hline Mimura et al. [28] & Bi-plane X-ray & -4 & 38 & 3.7 & 2.9 & 2.1 & 2.7 & 3.2 & - \\
\hline Present study & 3D CT & $2.4(1.8)$ & $38.5(4.7)$ & $3.1(1.1)$ & $4.0(1.6)$ & $5.3(1.5)$ & $4.6(1.8)$ & $2.3(1.3)$ & $1.6(0.9)$ \\
\hline
\end{tabular}


The segmental motions measured in previous studies have been less than $2^{\circ}$, especially in axial rotation [24]. Therefore, we have implemented a volume merge method in an effort to refine the accuracy of the Eigen vector method. Similar methods have been used for in vivo measurement of kinematics of carpal bone, knee joint, hip joint and cervical spine with high accuracy [25-31].

Studies which have measured segmental rotation due to an external axial rotation are rare. Previous representative data for axial rotation of the cervical spine are shown in Table I. In vivo, results from conventional CT present larger values at all levels compared with our results except C2-C3 [12, 32]. Conventional CT allows an alignment of the gantry only in the sagittal plane, not in the frontal plane. Tilted vertebrae could be transected obliquely to a different extent in the axial plane, owing to coupled motion [8]. This would impair the measurement of pure axial rotation, potentially leading to these differences in results. Conversely, an in vivo study by Mimura et al. [23] and an in vitro study by Panjabi et al. [21] yielded smaller values of axial rotation than our investigation except C1-C2. Those different results compared with ours might come from small head rotation $\left(52.5^{\circ}\right.$ between occiput and C7 to one side) in the former and the small loads applied for axial torque (a pure moment of $1 \mathrm{Nm}$ for axial torsion) in the latter. In an in vitro study, Miura et al. [33] recommended a pure moment of $4 \mathrm{Nm}$ for axial torque to simulate in vivo-like cervical motions, and our results support this concept.

The present study has several potential limitations. First, the study included only a small number of healthy, young persons. Therefore, no comparable data can be determined for an elderly group of asymptomatic persons. Second, the persons were positioned supine, not in the upright position. The differences of postures may have an effect on spinal motions.

In conclusion, we have studied three-dimensional, in vivo motions in healthy individuals and revealed that three-dimensional cervical segmental motions can be accurately measured with a non-invasive method. These findings will be helpful as the basis for understanding cervical spine movement in rotation and abnormal conditions. The presented data also provide baseline segmental motions for the design of prostheses for the cervical spine.

\section{References}

1. Buonocore E, Hartman JT, Nelson CL. Cineradiograms of cervical spine in diagnosis of soft-tissue injuries. JAMA 1966; 198: 143-7.

2. Panjabi MM, White AR, Johnson RM. Cervical spine mechanics as a function of transection of components. J Biomech 1975; 8: 327-36.
3. Kristjansson E, Leivseth G, Brinckmann P, Frobin W. Increased sagittal plane segmental motion in the lower cervical spine in women with chronic whiplash-associated disorders, grades I-II: a case-control study using a new measurement protocol. Spine (Phila Pa 1976) 2003; 28: 2215-21.

4. Hino H, Abumi K, Kanayama M, Kaneda K. Dynamic motion analysis of normal and unstable cervical spines using cineradiography. An in vivo study. Spine (Phila Pa 1976) 1999; 24: 163-8.

5. Dai L. Disc degeneration and cervical instability. Correlation of magnetic resonance imaging with radiography. Spine (Phila Pa 1976) 1998; 23: 1734-8.

6. Ng HW, Teo EC, Lee KK, Qiu TX. Finite element analysis of cervical spinal instability under physiologic loading. J Spinal Disord Tech 2003; 16: 55-65.

7. Reitman CA, Mauro KM, Nguyen L, Ziegler JM, Hipp JA. Intervertebral motion between flexion and extension in asymptomatic individuals. Spine (Phila Pa 1976) 2004; 29: 2832-43.

8. Ishii T, Mukai Y, Hosono N, et al. Kinematics of the subaxial cervical spine in rotation in vivo three-dimensional analysis. Spine (Phila Pa 1976) 2004; 29: 2826-31.

9. Lim TH, Eck JC, An HS, McGrady LM, Harris GF, Haughton VM. A noninvasive, three-dimensional spinal motion analysis method. Spine (Phila Pa 1976) 1997; 22: 1996-2000.

10. Rogers BP, Haughton VM, Arfanakis K, Meyerand ME. Application of image registration to measurement of intervertebral rotation in the lumbar spine. Magn Reson Med 2002; 48: 1072-5.

11. Antonaci F, Ghirmai S, Bono G, Nappi G. Current methods for cervical spine movement evaluation: a review. Clin Exp Rheumatol 2000; 18: S45-52.

12. Dvorak J, Hayek J, Zehnder R. CT-functional diagnostics of the rotatory instability of the upper cervical spine. Part 2. An evaluation on healthy adults and patients with suspected instability. Spine (Phila Pa 1976) 1987; 12: 726-31.

13. Ochia RS, Inoue N, Renner SM, et al. Three-dimensional in vivo measurement of lumbar spine segmental motion. Spine (Phila Pa 1976) 2006; 31: 2073-8.

14. Panjabi M, Yamamoto I, Oxland T, Crisco J. How does posture affect coupling in the lumbar spine? Spine (Phila Pa 1976) 1989; 14: 1002-11.

15. Crisco JJ, Pike S, Hulsizer-Galvin DL, Akelman E, Weiss AP, Wolfe SW. Carpal bone postures and motions are abnormal in both wrists of patients with unilateral scapholunate interosseous ligament tears. J Hand Surg Am 2003; 28: 926-37.

16. Panjabi MM, Summers DJ, Pelker RR, Videman T, Friedlaender GE, Southwick WO. Three-dimensional loaddisplacement curves due to forces on the cervical spine. J Orthop Res 1986; 4: 152-61.

17. Panjabi MM, Krag MH, Goel VK. A technique for measurement and description of three-dimensional six degree-of-freedom motion of a body joint with an application to the human spine. J Biomech 1981; 14: 447-60.

18. Dickey JP, Pierrynowski MR, Bednar DA, Yang SX. Relationship between pain and vertebral motion in chronic low-back pain subjects. Clin Biomech (Bristol, Avon) 2002; 17: 345-52.

19. Pearcy M, Portek I, Shepherd J. Three-dimensional x-ray analysis of normal movement in the lumbar spine. Spine (Phila Pa 1976) 1984; 9: 294-7.

20. Pearcy MJ. Stereo radiography of lumbar spine motion. Acta Orthop Scand Suppl 1985; 212: 1-45.

21. Panjabi MM, Crisco JJ, Vasavada A, et al. Mechanical properties of the human cervical spine as shown by three- 
dimensional load-displacement curves. Spine (Phila Pa 1976) 2001; 26: 2692-700.

22. Moroney SP, Schultz AB, Miller JA, Andersson GB. Loaddisplacement properties of lower cervical spine motion segments. J Biomech 1988; 21: 769-79.

23. Mimura M, Moriya H, Watanabe T, Takahashi K, Yamagata M, Tamaki T. Three-dimensional motion analysis of the cervical spine with special reference to the axial rotation. Spine (Phila Pa 1976) 1989; 14: 1135-9.

24. Harrison DE, Cailliet R, Harrison DD, Janik TJ, Troyanovich SJ, Coleman RR. Lumbar coupling during lateral translations of the thoracic cage relative to a fixed pelvis. Clin Biomech (Bristol, Avon) 1999; 14: 704-9.

25. Ishii T, Mukai $\mathrm{Y}$, Hosono N, et al. Kinematics of the upper cervical spine in rotation: in vivo three-dimensional analysis. Spine (Phila Pa 1976) 2004; 29: E139-44.

26. Crisco JJ, McGovern RD, Wolfe SW. Noninvasive technique for measuring in vivo three-dimensional carpal bone kinematics. J Orthop Res 1999; 17: 96-100.

27. Neu CP, McGovern RD, Crisco JJ. Kinematic accuracy of three surface registration methods in a three-dimensional wrist bone study. J Biomech Eng 2000; 122: 528-33.

28. Olivecrona L, Crafoord J, Olivecrona H, et al. Acetabular component migration in total hip arthroplasty using CT and a semiautomated program for volume merging. Acta Radiol 2002; 43: 517-27.

29. Olivecrona $\mathrm{H}$, Olivecrona L, Weidenhielm L, et al. Stability of acetabular axis after total hip arthroplasty, repeatability using CT and a semiautomated program for volume fusion. Acta Radiol 2003; 44: 653-61.

30. Sonenblum SE, Crisco JJ, Kang L, Akelman E. In vivo motion of the scaphotrapezio-trapezoidal (STT) joint. J Biomech 2004; 37: 645-52.

31. Dennis DA, Mahfouz MR, Komistek RD, Hoff W. In vivo determination of normal and anterior cruciate ligamentdeficient knee kinematics. J Biomech 2005; 38: 241-53.

32. Penning L, Wilmink JT. Rotation of the cervical spine. Spine 1987; 12: 732-8.

33. Miura T, Panjabi MM, Cripton PA, et al. A method to simulate in vivo cervical spine kinematics using in vitro compressive preload. Spine 2002; 27: 43-8. 